\title{
Apontamentos sobre duas representaçóes do mal divergentes
}

Janine Targino ${ }^{1}$

Resumo: As representaçóes do mal vigentes na Igreja Universal do Reino de Deus (IURD) e na Seicho-No-Ie mostram-se bastante divergentes. Se para a IURD é pujante a crença em demônios e no potencial que estes possuem para provocar os problemas, na cosmologia da Seicho-No-Ie a verdadeira fonte dos males é a mente humana, uma vez que ela é capaz de criar situaçóes de infortúnios. Partindo desta divergência fundamental, este artigo apresenta uma análise comparativa sobre os desdobramentos que ambas as representaçóes do mal manifestam na vida dos indivíduos de acordo com a adesão deles à IURD ou à Seicho-No- Ie. A principal conclusão alcançada pela pesquisa aponta que as diferentes concepçôes de mal observadas acionam práticas rituais e performances distintas nas duas instituiçôes religiosas estudadas.

Palavras-chave: Representação do Mal; Igreja Universal do Reino de Deus; Seicho-No-Ie; práticas rituais.

\section{Notes about two divergent representations of evil}

\begin{abstract}
The current representations of evil at Igreja Universal do Reino de Deus (IURD) and at Seicho-No-Ie are quite different. If for the IURD the belief in demons and the potential they have to cause problems is real, at Seicho-No-Ie cosmology, the true source of evil is the human mind, since it is capable of creating situations of misfortune. Starting from this fundamental divergence, this article presents a comparative analysis of the consequences that both representations of evil manifest in the lives of individuals' lives according to their adherence to the IURD or Seicho No Ie. The main conclusion reached by the research points out that the different conceptions of evil observed trigger different ritual practices and performances in the two studied religious institutions.
\end{abstract}

Keywords: Representation of Evil; Igreja Universal do Reino de Deus; Seicho-No-Ie; ritual practices.

\footnotetext{
Pós-doutora em Sociologia Política pela Universidade Estadual do Norte Fluminense Darcy Ribeiro (2018); doutora (2014); mestre (2010); bacharel; e licenciada em Ciências Sociais (2008) pela Universidade do Estado do Rio de Janeiro. Atualmente é professora e pesquisadora no Programa de Pós-graduação em Sociologia Política do IUPERJ-UCAM e professora na Universidade do Estado do Rio de Janeiro - UERJ. E-mail: janine.targino.silva@gmail.com
} 


\section{Introduçáo}

No Brasil, a variedade de representações do mal provenientes das religiôes é um fenômeno intimamente ligado à diversidade que impera em seu campo religioso. Estas representaçôes, por formarem um conjunto heterogêneo, muitas vezes mostram-se antagônicas entre si, como é o caso, por exemplo, das concepçóes de mal vigentes na Igreja Universal do Reino de Deus (IURD) e na Seicho-No-Ie. Enquanto a IURD possui como principal característica a crença em demônios e na ação maléfica destes sobre os indivíduos, a SeichoNo-Ie trabalha com uma perspectiva "psicologizada", em que os infortúnios são causados pela capacidade criativa da mente humana.

Para além desta diferença fundamental, deve-se ressaltar que a IURD e a SeichoNo-Ie são provenientes de matrizes religiosas bastante distintas. A primeira trata-se de um desdobramento do avanço do neopentecostalismo no Brasil e constitui um dos ícones do fenômeno denominado "terceira fase do pentecostalismo" (FRESTON, 1994). A segunda, em contrapartida, está baseada em uma matriz religiosa oriental que chegou ao Brasil, por volta de 1950 (PAIVA, 2005), através de um movimento de "orientalização do Ocidente" (CAMPBELL, 1997) profundamente influenciado pela crise da racionalidade ocidental e pela situação de reencantamento do mundo (ALBUQUERQUE, 2001). O fato de ambas coexistirem no campo religioso brasileiro possibilita uma análise comparativa que, neste artigo, concentrou-se nas características inerentes à representação do mal que a IURD e a Seicho-No-Ie sustentam em suas respectivas cosmologias.

Sendo assim, este artigo analisa a percepção dos indivíduos em torno das representaçóes do mal da IURD e da Seicho-No-Ie. Além disso, a forma pela qual estas representaçóes singularizam o cotidiano dos indivíduos de acordo com a adesão a uma destas instituiçôes religiosas também esteve no rol de elementos observados durante a pesquisa. Os dados aqui examinados foram obtidos por meio de entrevistas semiestruturadas e observação de campo.

Antes de prosseguir, é necessário esclarecer como a Seicho-No-Ie é tratada ao longo deste artigo. Há na Seicho-No-Ie uma tensão entre uma autodefinição ligada à sua origem, na qual seu fundador, Masaharu Taniguchi, a designava como uma religiấo, e uma autodefiniçáo mais atual, em que a Seicho-No-Ie é considerada uma filosofia de vida, que pode ou náo ser adotada como religiáo pelos seus adeptos. Nesta pesquisa, a Seicho-No-Ie foi observada como uma religiáo, visto que ela possui doutrina, rituais e crenças que lhe são próprios. Além do mais, o fato de os adeptos da Seicho-No-Ie se referirem à mesma como uma espécie de teodiceia também serve de dado para sustentar um ponto de vista que a observa como religião, e não apenas como filosofia de vida. 


\section{Seicho-No-Ie}

A Seicho-No-Ie foi fundada no Japão, em $1^{\circ}$ de março de 1930, por Masaharu Taniguchi (1893-1985), um $\mathrm{PhD}$ em filosofia que, antes de se dedicar à criação desta religião, escreveu diversos livros nos quais contestava a existência de Deus fundamentado na premissa de que "não poderia existir Deus em um mundo pautado no sofrimento e em desigualdades de todos os gêneros". Situada no grupo denominado por estudiosos como "novas religióes japonesas", a Seicho-No-Ie cresceu no pós-guerra (PAIVA, 2005), momento no qual também surgiram outras religióes, como a Soka Gakkai, a Perfect Liberty e a Igreja Messiânica Mundial (Johrei), em função do abalo sofrido pela religião oficial do Estado japonês, profundamente estruturada na crença na divindade do imperador e uma das principais bases da ideologia militarista.

Após escrever livros sobre ateísmo, Masaharu Taniguchi teria recebido de um anjo a revelação de que "o sofrimento e a dor não existem, visto que a matéria também não existe". Foi neste momento que ele se sentiu inspirado a fundar uma nova religião, denominada por ele "Seicho-No-Ie", que em japonês significa "Lar do Progredir Infinito". A criação desta religião considerou as características inerentes ao campo religioso japonês para que fosse possível alcançar aceitação. No Japão, as religiôes reconhecidas como tradicionais são o Catolicismo, o Budismo e o Xintoísmo. No entanto, não existe muita tolerância entre católicos e budistas, podendo-se até mesmo dizer que católicos dificilmente iriam a templos budistas e que os budistas muito provavelmente não frequentariam igrejas católicas. Porém, a relação entre católicos e o xintoísmo, assim como a relação entre budistas e o xintoísmo, é bastante diferente. No rol das religióes instaladas no Japão, o xintoísmo é visto como a mais tradicional, sendo respeitado não só por seus adeptos mas também pelos seguidores de outras religióes. Em vista disso, Masahari Taniguchi, preocupou-se em estruturar a Seicho-No-Ie em preceitos xintoístas, mas sem afastar-se completamente do budismo e do catolicismo, uma atitude que mostra o quanto o líder fundador dedicou-se à criação de condiçôes que viabilizassem a aceitação desta nova religião no campo religioso japonês ${ }^{2}$.

Ao chegar ao Brasil, como nos diz Paiva,

A Seicho-No-Ie foi introduzida primeiramente entre os colonos japoneses da Alta Paulista, tipicamente por meio de literatura religiosa, que continua um dos meios mais utilizados de divulgação. Com o relativo insucesso de propagação entre os japoneses da primeira geração, já portadores de uma religião, e entre os japoneses da segunda geração, atraídos pelo catolicismo como instrumento de inserção na sociedade brasileira, a Seicho-no-iê voltou-se, desde a década de 70, para os nãodescendentes de japoneses (PAIVA, 2005, p. 11).

\footnotetext{
2 Inclusive, o emblema criado para a Seicho-No-Ie busca unir os preceitos basilares das três principais religiōes do Japão. O círculo da Grande Harmonia, que encerra o sol, a lua e uma estrela, ou seja, o xintoísmo, o budismo e o cristianismo, mostra uma verdadeira união simbólica entre as tradicionais religiôes do Japão.
} 
Desde então, a Seicho-No-Ie e outras novas religiôes japonesas vêm conquistando adeptos entre os não descendentes de japoneses no Brasil. Em 1991, apenas duas das novas religióes japonesas instaladas no Brasil tinham fiéis autodeclarados (TOMITA, 2004). Mas, no Censo de 2010, registrou-se o significativo número de 155.951 mil pessoas que se dividiam entre as igrejas orientais Messiânica, Seicho-No-Ie, Hare Krishna, Perfect Liberty, Tenrikyo e Mahicari.

\section{O Mal que eu "crio" - o ponto de vista da Seicho-No-Ie sobre o Mal}

A doutrina fundamental da Seicho-No-Ie sustenta que existe apenas o Jissô, que pode ser traduzido aproximadamente como realidade, verdade, mente e Deus (PAIVA, 2002). Dessa forma, distinguem-se dois planos: um que corresponde à realidade/Jissô e aquele que se refere ao fenômeno. No plano que corresponde à realidade, o homem existe como filho perfeito de Deus, imortal e sem qualquer ligaçáo com o pecado. Já no plano do fenômeno, o homem encontra-se em uma posição vulnerável e pode ser atingido pelo pecado, pelas doenças, pela morte e outros males. Todavia, o fenômeno é criado pela mente humana e, por isso, pode ser visto como algo ilusório. Para que os males possam ser curados, a doutrina da Seicho-No-Ie indica a importância da tomada de consciência do Eu verdadeiro, isto é, o entendimento de que o homem é filho perfeito de Deus (PAIVA, 2002).

Entre as atividades propostas pela instituição para que os adeptos cheguem à consciência do Eu verdadeiro estão as palestras semanais, seminários regionais, estaduais e nacionais e a prática diária da meditação Shinsokan, que é uma meditação contemplativa formada por várias mentalizaçôes. O principal objetivo desta meditação é levar o indivíduo a transcender o mundo fenomênico-material e entrar em contato com o mundo da imagem verdadeira, ou seja, o mundo perfeito e absoluto criado por Deus. Há a orientação para que a meditação seja realizada todos os dias, com saudaçáo, culto aos antepassados, culto aos anjinhos abortados, louvor aos apóstolos da Missão Sagrada, entre outras (WOJTOWICZ, 2004).

Nota-se que o mal, dentro da cosmologia da Seicho-No-Ie, não é visto como algo personificado. Segundo esta religião, o mal não existe por si mesmo, não tem possibilidade de ação individual e não está concentrado em uma entidade de perfil maligno, posto que constitui uma situaçáo totalmente criada pela mente humana ${ }^{3}$. Estar doente ou em problemas financeiros, por exemplo, representam momentos nos quais o indivíduo entra em contato de maneira equivocada com o mundo fenomênico-material, a saber, com o "mundo" criado através da capacidade criativa da mente humana. Náo há, dentro das categorias usadas pela SeichoNo-Ie, espaço para o entendimento de que as situaçóes ruins vivenciadas pelo indivíduo são condiçóes impostas por entidades malignas. Pelo contrário, a Seicho-No-Ie sustenta que todo

\footnotetext{
3 É necessário enfatizar que, para a Seicho-No-Ie, tal capacidade criativa da mente humana advém das circunstâncias em que o homem fora criado. Para esta religião, é absolutamente legítima a afirmaçáo de que o homem é uma criação feita à imagem e semelhança de seu criador, Deus. Dessa maneira, a criatura possui as mesmas características de seu criador, inclusive a própria capacidade criativa, o que a torna tấo criadora quanto o seu criador. Entretanto, para a Seicho-No-Ie, a criaçáo de Deus constitui o mundo verdadeiro, enquanto a criação do homem é somente algo ilusório e sem existência concreta, posto que apenas o que é criado por Deus pode ser considerado como verdadeiramente existente.
} 
mal da humanidade é proveniente das "sombras da mente" tendo em vista que o mundo fora criado por Deus em sua mais absoluta perfeição e sem escassez de qualquer espécie. Deste modo, não parece incorreto dizer que o mal para a Seicho-No-Ie se trata de uma criação, uma vez que ele não possui existência independente da ação mental do indivíduo.

Contudo, se o mal é criado pela mente humana, é também somente através dela que ele pode ser eliminado. As práticas indicadas pela Seicho-No-Ie têm como ponto de convergência a ênfase na purificação da mente para que esta não "crie" o mal. A meditação Shinsokan é uma das práticas mais importantes neste sentido, pois tem o intuito de fazer com que o indivíduo ultrapasse a barreira do mundo fenomênico-material (o mundo ilusório) chegando de fato ao mundo perfeito (o mundo verdadeiro, criado por Deus).

Se o Mal é criado pela mente humana, em contrapartida, ele pode ou não ser legitimado no discurso. Por meio da análise das entrevistas feitas com adeptos dessa religião foi possível constatar que questóes como doenças, desemprego, infelicidade conjugal, entre outras, são vistas como irrelevantes e sem a menor existência concreta. Um dos entrevistados, AR, de 35 anos, adepto da Seicho-No-Ie há doze anos, ofereceu a seguinte declaração:

A gente (os adeptos da Seicho-No-Ie) só acredita naquilo que é eterno, aquilo que pode permanecer, e aquilo que pode permanecer, aquilo que é eterno, pra gente, é a vida, éo espirito. Então, a gente só acredita nas coisas, acredita de verdade, vamos dizer assim, nas coisas que são pautadas no espirito, que têm a sua base no espirito e nessa mente divina que cria o mundo de uma maneira perfeita. O restante, as doenças que as pessoas sofrem, as pobrezas que as pessoas sofrem, as crises econômicas ou as desarmonias no lar, seja lá o que for, são sombras da mente. (AR, de 35 anos, adepto da Seicho-No-Ie).

Considerar as doenças, as crises econômicas e a desarmonia no lar como inexistentes é o primeiro passo para transcender o mundo fenomênico-material e atingir o mundo verdadeiro. Dificilmente um adepto da Seicho-No-Ie irá legitimar em seu discurso qualquer tipo de problema com o qual esteja sofrendo. De fato, o discurso destes indivíduos é permeado pelo esforço em negar a existência dos problemas pautado na máxima de que todos os infortúnios não são nada mais que ilusóes surgidas no plano do fenômeno. A declaração de AA, 29 anos, adepta da religião há sete anos, serve perfeitamente para ilustrar este ponto:

Agora, neste momento, eu estou gripada. Mas veja bem, eu estou doente, mas não sou doente. Essa é a diferença. Se uma pessoa disser 'éu sou saudável', ela vai se tornar uma pessoa saudável. Se ela disser 'é sou doente', ela vai se tornar uma pessoa doente porque ela acredita nisso. É por isso que nós fazemos cerimônias de purificação da mente, pra que tudo aquilo que não nos pertence volte ao seu nada original. (AA, 29 anos, adepta da Seicho-No-Ie).

Igualmente, as oraçóes disponíveis no site $e^{4}$ oficial da Seicho-No-Ie corroboram esta atitude em relação aos problemas, ou seja, em relação ao mal. Novamente, deparamo-nos com

4 https://sni.org.br/ 
mais um conceito que precisa de tratamento especial para evitar seu emprego inadequado. Considerando que este artigo propóe uma comparaçáo entre determinados elementos das cosmologias da Seicho-No-Ie e da IURD, é imprescindível matizar o que vem a ser oração para cada uma delas. Para a IURD, a oraçáo é o momento no qual o indivíduo entra em contato com a divindade para lhe solicitar algo ou para lhe agradecer alguma graça recebida. Entretanto, para essa religiáo, a ideia, a prática da oração adquire novas nuances oriundas das peculiaridades de sua cosmologia. Segundo, com o que fora exposto anteriormente, a Seicho-No-Ie percebe o mundo como uma criação perfeita de Deus, onde não há escassez de nenhuma espécie. Sendo assim, náo há necessidade de realizar pedidos durante as oraçóes, pois tudo o que o homem precisa já existe, basta que ele saiba a forma correta de usufruir todas as benesses do mundo. A pauta comum das oraçóes feitas pelos adeptos dela é o agradecimento a tudo de bom que existe. Alguns exemplos de oraçóes divulgadas no site oficial desta religião demonstram com clareza este aspecto.

\section{Oração para conseguir fazer tudo}

Como filho de Deus, recebi dEle a força para fazer todas as coisas. Por isso, jamais digo que não consigo fazer algo. As matérias escolares ou os trabalhos que me foram dados pelo professor ou por meus pais, executo-os docilmente, pois acho que posso fazê-los. Com certeza, a força de Deus se manifestará, e conseguirei tudo fazer. Muito obrigado.

Oração para ser sempre saudável

A Vida de Deus se alojou dentro de mim e tornou-se minha vida. Minha vida é Vida sagrada de Deus; por isso, sou sempre perfeito e saudável. Quando por acaso eu me machuco ou adoeço, a Vida de Deus cura o meu corpo internamente, através de Sua infinita força. Por isso, sou sempre saudável e, mesmo que me canse, logo me recupero. Muito obrigado.

Oraçáo de segurança

Deus é Amor infinito. O infinito Amor de Deus sempre me protege. Por isso, estou sempre seguro. Com a orientação de Deus, desvio-me naturalmente dos lugares perigosos. Estou sempre protegido por Deus e, por isso, não temo nem sinto medo em nenhum momento, pois age a Sabedoria adequada. Muito obrigado.

Nestas orações estão presentes apenas séries de afirmaçôes. Em momento algum são feitos pedidos. Aqui, é possível encontrar expressóes como "com a orientação de Deus, desviome naturalmente dos lugares perigosos" e não "Deus, livra-me dos caminhos perigosos", ou então "minha vida é a vida sagrada de Deus, por isso sou sempre perfeito e saudável", e jamais "Deus, dê-me saúde". Esta modalidade peculiar de oração corporifica as informaçôes até aqui apresentadas a respeito da concepção de mal presente na cosmologia da Seicho-No-Ie. Tendo em mente que para esta religiáo o mal, representado pelas várias modalidades de infortúnios 
com os quais os indivíduos sofrem, simplesmente não existe para além das fronteiras do mundo fenomênico-material, o mais importante a ser feito é a purificação da mente para que esta não legitime a existência ilusória do mal. As oraçôes, dentro da perspectiva nativa, além de diluírem a existência de um amplo conjunto de problemas, também promovem uma "limpeza na mente", evitando que ela crie o mal.

Um outro aspecto interessante a ser observado no âmbito das oraçóes indicadas pela Seicho-No-Ie é a reverência, um ato bastante arraigado na cosmologia desta religiáo. A doutrina da Seicho-No-Ie considera que a reverência à vida é a base do ensinamento do mestre ${ }^{5}$, já que, ao agradecermos e vivificarmos uns aos outros, reverenciamos a própria vida (WOJTOWICZ, 2004: 55). Todas as orações divulgadas no site terminam com a frase "muito obrigado". Isso ilustra, mais uma vez, o quanto a crença na não existência dos males é relevante dentro da cosmologia da Seicho-No-Ie, pois, uma vez que todo o necessário para viver bem e feliz já existe no mundo verdadeiro, não há necessidade de realizar qualquer pedido a Deus. Só resta ao indivíduo agradecer tudo que foi trazido à existência por meio de Sua criação. Reverenciar, na perspectiva da Seicho-No-Ie, também constitui um ato ligado à harmonização da vida. De acordo com BM, 43 anos, adepto da Seicho-No-Ie há cinco anos:

O natural é que a gente não tenha mágoa das pessoas, que a gente não odeie as pessoas, que a gente ame as pessoas, que a gente elogie as pessoas e que a gente reverencie a vida. Se as pessoas fazem isso, é natural que a vida delas seja harmoniosa, que elas não tenham desarmonia no lar. Então, se a desarmonia no lar está acontecendo é porque alguém, em algum momento, resolveu ficar magoado, ou resolveu subjugar o outro. (BM, 43 anos, adepto da Seicho-No-Ie).

A reverência constitui, no âmbito da cosmologia da Seicho-No-Ie, um ato indispensável para uma vida feliz e em concordância com os preceitos divinos.

\section{Igreja Universal do Reino de Deus - IURD}

A Igreja Universal do Reino de Deus (IURD) foi fundada no ano de 1977 por Edir Bezerra Macedo, na zona norte da cidade do Rio de Janeiro. Começando com a veiculaçáo de programas radiofônicos e, posteriormente, dedicando-se também à programação televisiva e à mídia impressa, a Igreja Universal conseguiu arregimentar cada vez mais fiéis para as suas fileiras ao longo das últimas décadas.

As Teologias da Prosperidade e da Batalha Espiritual, de acordo com os pesquisadores que dedicaram páginas de estudos à IURD, são elementos estruturais da cosmologia desta igreja. A Teologia da Prosperidade traz para ordem do dia uma abordagem que se identifica profundamente com a autoajuda e com a valorização do indivíduo, além de agregar elementos para a crença na cura, na prosperidade e no poder da fé através da confissão da palavra

\footnotetext{
5 Mestre é a forma pela qual os adeptos à Seicho-No-Ie se referem a Masaharu Taniguchi.
} 
(MAGALHÃES; SOUZA, 2002). Com a implementação da Teologia da Prosperidade, o cristão passa a entender que tem o total direito de usufruir o que há de melhor no mundo, não só em termos de riqueza material mas também no que diz respeito a ter uma saúde perfeita e uma vida feliz e livre de problemas (MAGALHÂES; SOUZA, 2002).

A Teologia da Batalha Espiritual pode ser definida como um conjunto de preceitos que sustentam a importância da evangelização (a pregação da palavra cristã) e da luta contra o demônio, uma entidade que está presente em toda forma de mal que se faz ou que se sofre e nas práticas religiosas não cristãs (MARIZ, 1997a). Dessa forma, a Igreja Universal acredita na existência de religiôes demoníacas, comumente classificando as religiōes espíritas e afro-brasileiras como tais (SILVA, 2007). Para os fins deste artigo, é indispensável a análise dos desdobramentos da Teologia da Batalha Espiritual sobre as práticas rituais e cosmologia iurdianas.

\section{O Mal que eu "creio" - o ponto de vista da Igreja Universal do Reino de Deus sobre o Mal}

Segundo a cosmologia iurdiana, a ação demoníaca é a fonte de todo o mal (MARIZ, 1997b). Em contrapartida, no polo oposto, Deus constitui o único ponto de onde emana bem-estar e salvação para os problemas deste mundo (TARGINO, 2008). Forma-se, então, o binômio Deus X demônio, muito presente no conjunto das igrejas neopentecostais, do qual a igreja Universal é uma das maiores referências. Para a IURD, o mal está personificado em uma entidade que o tem como essência, ou seja, o mal tem existência própria e pode agir voluntariamente sobre a vida dos indivíduos, causando-lhes infortúnios. No bojo das narrativas iurdianas, as entidades do panteão afro-brasileiro figuram como os principais agentes do mal (SILVA, 2007; TARGINO, 2008).

A crença em demônios e em sua ação maléfica mobiliza todo um conjunto de crenças e açôes rituais. Atualmente, a IURD dedica dois dias durante a semana para a realização de cultos voltados para a "amarraçáo" dos demônios: as terças-feiras, quando são feitas as Sessóes Espirituais do Descarrego, e as sextas-feiras, dias nos quais é promovida a Corrente da Libertação. Em ambos os cultos, ocorre um confronto direto entre os fiéis e os demônios que devem ser expulsos. Neste confronto entre bem e mal, as oraçóes realizadas pelos regentes dos cultos e acompanhadas pelos fiéis ganham destaque em função da pauta fundamental que seguem, permeada pela acusação constante dos demônios pelos mais variados motivos. Para ilustrar este aspecto, segue o trecho de uma oração realizada pelo pastor em um dos cultos de descarrego observados durante a pesquisa de campo:

Senhor Jesus, esse jejum que estamos fazendo (o jejum era parte de um "propósito") é para quebrar esta casta de demônios. Se esta casta de demônios estiver na vida dessas pessoas vai sair agora, vai sair agora! Em nome de Jesus, o demônio que recebeu um trabalho de macumba, um trabalho de final de ano, um trabalho 
de feitiço pra atingir essa pessoa, pra atingir a família dessa pessoa, pra atingir a casa dessa pessoa, vamos! Você - o demônio - colocou enfermidades, uma dor, você colocou enfermidade, inflamação, enxaqueca, dor de cabeça constante, você ganhou um trabalho de macumba com cachaça pra destruir essa pessoa, pra deixar essa pessoa desempregada, vamos encosto! Vamos!” E pede para que os presentes repitam, com as mãos na cabeça: "em nome do Senhor Jesus, encosto de doença, de miséria, agora, sai! Sai!.

Estas numerosas acusaçôes feitas aos demônios (que são responsabilizados por doenças, problemas familiares, desemprego) nos mostram que a representação iurdiana do mal é portadora de múltiplos atributos no que tange aos malefícios que pode provocar. Além disso, comportamentos classificados como desviantes, como por exemplo, o alcoolismo, o uso de drogas e a prostituiçáo, sempre são apontados como o resultado da ação demoníaca e jamais como um ato sobre o qual repousa exclusivamente a responsabilidade de seu autor (MARIZ, 1997b).

Nas músicas cantadas durante os cultos da Sessão Espiritual do Descarrego e da Corrente da Libertação também está presente o tom de ataque às forças do mal. Semelhante às oraçóes, as músicas citam constantemente a palavra "sai", que simboliza, na cosmologia iurdiana, a palavra de ordem definitiva para a expulsão de demônios. Das anotaçóes feitas no caderno de campo foi extraído o seguinte trecho.

A imposição de mãos feita pelo bispo demora bastante para terminar, pois a quantidade de pessoas sobre o altar é muito grande. O bispo pede entáo que a música volte, e o tecladista recomeça: o fogo cai, cai, cai, cai, cai, encosto sai, sai, sai, sai, sai, e nós vivemos louvando ao Senhor, e nós vivemos louvando ao Senhor... O nome de Jesus é poderoso, não há quem possa derrotar, o nome de Jesus é poderoso, não há quem possa derrotar, e o encosto sai, a macumba sai... a minha fé é poderosa pela graça de Jesus, a minha fé é poderosa pela graça de Jesus, e os encostos vão saindo, porque não resistem à luz! Sai, sai, sai, em nome de Jesus!

Do mesmo modo que as oraçôes, outras açóes rituais implementadas durante os cultos colaboram para ilustrar a forma como se estrutura o embate entre fiéis e demônios, ou, em termos mais gerais, entre bem e mal. Entre estas açóes rituais a prática mais comum é o exorcismo, momento no qual o mal ganha corpo e voz através do indivíduo em que ele se manifesta. Precede o exorcismo uma oração chamada pelos adeptos da IURD de "oração forte", que segue os moldes da oração apresentada acima. Associada à oração, pastores e obreiros realizam a imposição de mãos e, na grande maioria dos casos, as manifestaçóes dos demônios acontecem somente por meio deste. Partindo deste dado, parece razoável a conclusão de que há uma associaçáo imediata entre o papel que obreiros e pastores representam nos cultos e na hierarquia da Igreja e a autoridade para expulsar demônios das pessoas, posto que, de acordo com a cosmologia iurdiana, o exorcismo trata-se do principal meio para a neutralização da ação demoníaca na vida de um indivíduo. No discurso nativo, o exorcismo é comumente apontado 
como a prática fundamental do processo de libertação, que é composto por um conjunto de procedimentos aplicados com a intenção de libertar as pessoas do jugo demoníaco.

Sinteticamente, podemos definir o exorcismo como a ocasiáo na qual o demônio que assola um indivíduo com infortúnios manifesta-se em seu corpo, sendo posteriormente expulso por obreiros e pastores. Contudo, outras açóes rituais que utilizam elementos rituais dos mais variados tipos são capitais para que o mal realmente seja afastado. O uso de rosas, sal grosso, arruda, água fluidificada, entre outros, é algo bastante presente nos cultos, pois incorporam a função de auxiliadores no processo de expulsão do mal não só da vida do fiel, mas também de toda sua família. As rosas usadas durante as Sessóes Espirituais do Descarrego são um bom exemplo disso. Durante o período da pesquisa de campo, estas rosas eram distribuídas na igreja às terças-feiras. A função das rosas era fundamental para a eficácia da sequência ritual que tinha início na igreja às terças-feiras, passava pela casa do fiel, e terminava no domingo, com o retorno da rosa à igreja.

Segundo os regentes dos cultos, a rosa ungida teria o poder de absorver todo o mal instalado na casa do fiel. A rosa sempre deveria ser colocada no lugar mais alto da casa, e deixada lá até o domingo seguinte para então ser levada de volta à igreja, onde seria queimada ou levada pelo pastor ou bispo para ser jogada no mar ou em um rio. Segundo as explicaçóes dadas pelos regentes dos cultos, quanto mais seca a rosa ficasse, maior também seria a intensidade da "carga negativa" da casa onde ela estava.

Uma outra dimensão importante da representação do mal vigente na IURD é o caráter contínuo da luta travada contra os demônios. Não há momento de descanso ou de tranquilidade dentro desta batalha espiritual. Ainda que o fiel tenha concluído seu processo de libertação e sinta-se livre da influência demoníaca no plano pessoal, há a necessidade de lutar contra os demônios que atuam na vida de seus familiares, contra o demônio que atribula a sua vida financeira, entre outros. A guerra contra as forças do mal nunca cessa e o arsenal de açóes e elementos rituais usados para atacar o inimigo guarda peculiaridades que o identificam com as estruturas básicas que sustentam a cosmologia iurdiana.

\section{Consideraçóes finais}

$\mathrm{Na}$ tentativa de construir uma análise comparativa entre as representações do mal presentes nas IURD e na Seicho-No-Ie, foram apresentados alguns pontos sobre os quais estas instituiçóes divergem. O principal deles diz respeito à origem dos males com os quais os indivíduos sofrem. Enquanto a Seicho-No-Ie adota um ponto de vista mais psicologizado sobre o Mal, em que todos os problemas físicos, sentimentais, financeiros, entre outros, são causados pela capacidade criativa da mente humana, a IURD enfatiza que a existência e ação de entidades malignas são as responsáveis por todos os infortúnios que atingem os indivíduos.

Partindo destas representaçóes divergentes do mal, igualmente foi possível observar que os rituais adotados na IURD e na Seicho-No-Ie são bastante particulares. Se a Seicho-No-Ie sublinha a importância da realização de rituais para a purificação da mente, com a intenção de 
evitar a criação do mal, a IURD aplica todo um conjunto de açôes voltadas para a expulsão dos demônios que são responsabilizados por provocarem malefícios de todas as naturezas.

Assim, espera-se ver compartilhada entre os adeptos da IURD a crença em demônios, que são, segundo o discurso nativo, entidades com existência individual, personalidade, capacidade para atuar voluntariamente e absolutamente impulsionadas pela vontade de infligir sofrimentos aos homens. Sobre esta concepção de mal estrutura-se toda a lógica da Teologia da Batalha Espiritual, pois, sendo o Mal um ser com existência própria, ele deve ser combatido enquanto um inimigo declarado. Este combate leva os indivíduos a participarem com afinco de ações rituais elaboradas com a finalidade de neutralizar a ação dos demônios. Essa é entendida como a única via possível para a resolução de qualquer tipo de problema.

Em contrapartida, no conjunto de adeptos da Seicho-No-Ie é comum que os indivíduos tomem parte de uma crença na oposiçáo estabelecida entre o mundo criado por Deus, considerado o mundo verdadeiro, e o mundo fenomênico-material, criado pelas sombras da mente humana. Esta construção bipolar torna-se possível em função da crença nativa na capacidade criativa da mente humana. Se é das sombras da mente que surgem todos os males com os quais os indivíduos sofrem, o verdadeiramente necessário é a purificação da mente em rituais praticados constantemente. Com a purificação da mente os problemas que existem deixam de ser legitimados e outros eventos negativos que poderiam surgir não mais encontram terreno propício para isso. O mal, para o adepto da Seicho-No-Ie, não possui personalidade, ação voluntária e individualidade, posto que ele é apenas uma manifestação da mente humana.

Para além das diferenças que colocam a IURD e Seicho-No-Ie em polos opostos e mutuamente excludentes, deve-se considerar também que elas possuem vários aspectos em comum. Tanto a IURD quanto a Seicho-No-Ie expandem-se internacionalmente a passos largos, fato que corrobora o que muitos autores dizem sobre as propícias condiçóes atuais para a difusão global de vários grupos religiosos (CASTILHO; GODOY, 2006; MATSUE, 2002; ORO, 2004). O próprio encontro mútuo destas religióes em solo brasileiro é um produto da globalização (MASANOBU, 2004). Além disso, ambas as religiôes estudadas possuem uma "concepção vitalista da salvação", em que se prioriza a conquista da salvaçáo neste mundo, indo contra o aspecto transcendente e de negação deste mundo, tão forte nas cosmologias das religióes tradicionais (MASANOBU, 2004). Dada a relevância destes pontos de convergência entre IURD e Seicho-No-Ie, espera-se que eles sejam adequadamente trabalhados em pesquisas posteriores.

\section{Referências Bibliográficas:}

ALBUQUERQUE, Leila Marrach Basto de. Oriente: fonte de uma geografia imaginária. Revista de estudos da religiáo (REVER), PUC-SP, n. 3, pp. 114-125, 2001.

CAMPBELL, Colin. A orientalização do ocidente: reflexôes sobre uma nova teodicéia para um novo milênio. Religiáo e Sociedade, v.18, n. 1, pp. 5 a 21, 1997.

CASTILHO, Gilberto Baptista; GODOY, Marília Gomes Ghizzi. A presença de valores 
orientais na cultura brasileira: as novas religióes japonesas. Revista de Ciências Humanas, Florianópolis, EDUFSC, n. 39, pp. 67-81, 2006.

FRESTON, Paul. Breve história do pentecostalismo brasileiro. In ANTONIAZZI, Alberto et al. Nem anjos nem demônios: interpretaçóes sociológicas do pentecostalismo. Petrópolis, RJ: Vozes, pp. 67-162, 1994.

MAGALHAES, Marionilde Brepohl de Dias; SOUZA, Etiane Caloy Bovkalovski. Os pentecostais: entre fé e política. Revista Brasileira de História, São Paulo, v. 22, n. 43, pp. 85-108, 2002.

MARIZ, Cecília. A teologia da guerra espiritual: uma revisão bibliográfica. Anais. "VII Jornadas de Alternativas Religiosas na América Latina”, Buenos Aires. Religión e Identidad, 1997a.

O Demônio e os pentecostais no Brasil. In: BIRMAN, Patrícia; NOVAES, Regina; CRESPO, Samira (Orgs). O mal à brasileira. Rio de Janeiro: EdUERJ, 1997b

MASANOBU, Yamada. "A concepção vitalista da salvação" no Brasil: as novas religiōes japonesas e o Pentecostalismo. Revista de estudos da religiáo (REVER), PUC-SP, n. 3, pp. 29-49, 2004.

MATSUE, Regina Yoshie. A expansão internacional das novas religióes japonesas: um estudo sobre a Igreja Messiânica Mundial no Brasil e na Austrália. Revista de estudos da religiáo (REVER), PUC-SP, n. 4, pp. 1-19, 2002.

ORO, Ari Pedro. A presença religiosa brasileira no exterior: o caso da Igreja Universal do Reino de Deus. Estudos Avançados, São Paulo, v. 1, n. 52, pp. 139-156, 2004.

PAIVA, Geraldo José de. Novas religiôes japonesas e sua inserção no Brasil: discussóes a partir da psicologia. Revista da USP, São Paulo, n. 22, pp. 208-217, 2005.

Imaginário e simbólico: aspectos psicológicos na adesão à Seicho No Iê e à PL Instituição Religiosa Perfeita Liberdade. Revista de estudos da religiáo (REVER), PUC-SP, n. 2, pp. 74-84, 2002.

TARGINO, Janine. De demônio a "encosto”, de ex-pai-de-santo a "ex-servo dos encostos": um estudo sobre a "Sessão Espiritual do Descarrego" da Igreja Universal do Reino de Deus. Monografia. Instituto de Filosofia e Ciências Humanas, Universidade do Estado do Rio de Janeiro. 2008.

SILVA, Vagner Gonçalves da. Neopentecostalismo e religióes afro-brasileiras: Significados do ataque aos símbolos da herança religiosa africana no Brasil contemporâneo. Mana, Rio de Janeiro, v. 13, n.1, pp. 207-236, 2007.

TOMITA, Andréa Gomes Santiago. As novas religióes japonesas como instrumento de transmissão de cultura japonesa no Brasil. Revista de Estudos da Religião (REVER), PUCSP, n. 3, pp. 88-102, 2004.

WOJTOWICZ, Licéria. A expressão da ideologia no artigo do mestre. Dissertação. Cento de Artes e Letras, Universidade Federal de Santa Maria. 2004. 